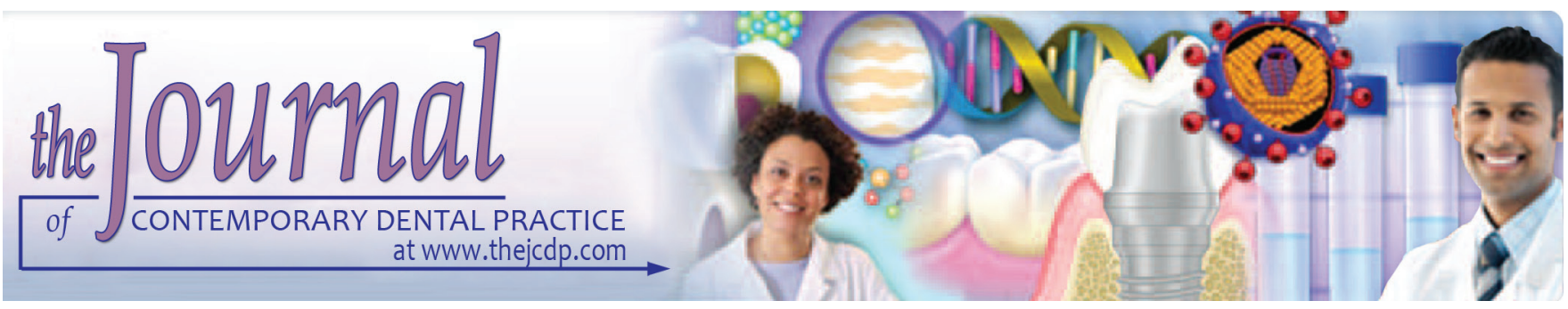

\title{
Assessment of Oral Hygiene Knowledge, Practices, and Concepts of Tobacco Usage among Engineering Students in Bhubaneswar, Odisha, India
}

\author{
${ }^{1}$ Alokenath Bandyopadhyay, ${ }^{2}$ Lipsa Bhuyan, ${ }^{3}$ Abikshyeet Panda, ${ }^{4}$ Kailash C Dash
}

${ }^{5}$ Malvika Raghuvanshi, ${ }^{6}$ Shyam S Behura

\begin{abstract}
Aim: This study aimed to assess oral hygiene-related knowledge and practices among engineering students of Bhubaneswar city and also to evaluate the concepts about the side effects of tobacco usage among those students.

Materials and methods: The study was conducted using a self-administered, close-ended questionnaire to assess the oral hygiene knowledge and practices and study the concepts on tobacco usage among 362 engineering students of Bhubaneswar city, Odisha, India. The obtained data were statistically analyzed using Statistical Package for the Social Sciences software version 20.0.

Results: This survey found that $26.51 \%$ of the students had never visited a dentist. Nearly $43.64 \%$ of the participants were cognizant of the fact that improper brushing is the reason of tooth decay. About $47 \%$ of the participants consumed alcohol and $32.6 \%$ had the habit of chewing tobacco, though $80 \%$ were aware that use of smokeless tobacco can impair oral health and cause cancer and use of alcohol has detrimental effect on oral health.
\end{abstract}

Conclusion: Knowledge with respect to oral health among engineering students of Bhubaneswar city is adequate regarding using fluoridated toothpaste and flosses. However, an unhealthy snacking habit, overusage of toothbrushes, consumption of alcohol, and practicing tobacco habit show the lack of oral health knowledge in these students.

Clinical significance: Our study provides an idea about the present scenario in terms of oral hygiene and tobacco usage

\footnotetext{
${ }^{1-6}$ Department of Oral Pathology and Microbiology, Kalinga Institute of Dental Sciences, Kalinga Institute of Industrial Technology University, Bhubaneswar, Odisha, India

Corresponding Author: Lipsa Bhuyan, Department of Oral Pathology and Microbiology, Kalinga Institute of Dental Sciences, Kalinga Institute of Industrial Technology University Bhubaneswar, Odisha, India, Phone: +919439892654, e-mail: bhuyanlipsa@gmail.com
}

in young individuals. This can form the basis for oral health education and tobacco cessation program. Moreover, as the habit of tobacco usage starts early during college life, adequate knowledge about its ill-effects would prevent deadly diseases, such as potentially malignant disorders and oral cancer.

Keywords: Attitude, Engineering students, Knowledge, Oral hygiene, Tobacco usage.

How to cite this article: Bandyopadhyay A, Bhuyan L, Panda A, Dash KC, Raghuvanshi M, Behura SS. Assessment of Oral Hygiene Knowledge, Practices, and Concepts of Tobacco Usage among Engineering Students in Bhubaneswar, Odisha, India. J Contemp Dent Pract 2017;18(6):423-428.

Source of support: Nil

Conflict of interest: None

\section{INTRODUCTION}

Oral hygiene is the practice of maintaining a clean oral cavity to prevent dental problems, such as dental cavities, gingivitis, periodontitis, and bad breath. Plaque and calculus are the main causes of gum disease and tooth decay. Proper oral hygiene is not only about clean teeth and fresh breath but it is also one of the best ways to help maintain good overall health. Oral health is a fundamental part of the general health and well-being of an individual. It can be achieved by maintaining a good oral hygiene. On the contrary, many studies have been carried out stating the detrimental effects of tobacco usage on oral health. Smoking and other tobacco products interfere with the normal functioning of cells of periodontium and lead to gum disease. ${ }^{1,2}$

Oral hygiene practices, such as brushing regularly, using fluoridated tooth paste, using aids, such as floss to clean interdental spaces, avoiding in-between meals, changing toothbrush at regular intervals, visiting the dentist regularly, and avoiding tobacco products 
holistically assist in accomplishing proper oral health. ${ }^{1}$ Despite a decline in dental caries in developing countries, there is still a high prevalence of oral diseases. A dramatic change in the prevalence of dental caries in adolescents of most Western industrialized countries may be due to changing living conditions, adoption of healthy, and improved lifestyle. ${ }^{3}$

The students of today are the future citizens of India. Their attitude and practice on oral health and knowledge about tobacco use play a remarkable role in setting up a better future. Studies have shown a change in the patterns of oral diseases, awareness on oral health, and knowledge and positive attitude toward dental health. Many studies have been carried out on oral health habits, knowledge, and attitude of health professionals. ${ }^{4-6}$ The aim of our study was to assess the knowledge on oral hygiene practices and ill-effects of tobacco usage among nonhealth professional students in Bhubaneswar, Odisha, India.

\section{MATERIALS AND METHODS}

A modified American Dental Association-recommended oral self-care questionnaire was distributed among 400 students of a private engineering college in Bhubaneswar, Odisha, India. This structured self-administered questionnaire was divided into three parts and contained a total of 16 close-ended questions. The first part consisted of the demographic data. The second part comprised 10 questions about oral hygiene practices and the third part had questions on knowledge about the consequences of tobacco.

Only those students present on the day of the study and those willing to participate were included in the study. The students who were not present on the day and those unwilling to participate were excluded from the study. The nature and purpose of the study was explained to the participants before the survey. The questionnaire was distributed in their respective classrooms and once answered it was collected. Incompletely filled questionnaires (38 in number) were discarded.

The data of the remaining 362 questionnaires were tabulated and statistically analyzed. Statistical analysis of the obtained data was done using Statistical Package for the Social Sciences software, version 20.0. Chi-square test was used to estimate the difference in terms of age, gender, and knowledge scores. $\mathrm{p} \leq 0.05$ was considered statistically significant.

\section{RESULTS}

Out of the 362 students, 271 (79.4\%) were males with a mean age of $21.63 \pm 1.81$ years and $91(21.63 \%)$ were females with a mean age of $21.30 \pm 2.06$ years (Table 1 ). Majority (63.5\%) of the participants brushed once a day
Table 1: Number and age of the study population

\begin{tabular}{|c|c|c|c|c|}
\hline Gender & Total (n) & $\begin{array}{l}\text { Percentage } \\
\text { of study } \\
\text { population }\end{array}$ & Mean $\pm S D$ & $p$-value \\
\hline Male & 271 & 79.4 & $21.63 \pm 1.81$ & \multirow{3}{*}{$\begin{array}{l}\text { Chi-square }= \\
21.09 p=0.02(S)\end{array}$} \\
\hline Female & 91 & 25.1 & $21.30 \pm 2.06$ & \\
\hline Total & 362 & 100 & $21.55 \pm 1.90$ & \\
\hline
\end{tabular}

SD: Standard deviation

whereas only $25.4 \%$ of the students brushed twice daily. Nearly $45.6 \%$ of the students always used fluoridated toothpaste whereas $14.3 \%$ have never used. Around $37 \%$ have never flossed their teeth. The habit of snacking between meals at a frequency of once a day, twice a day, and more than twice a day was 33.33, 20.99, and 33.70\% respectively. Nearly $34.53 \%$ of the students changed their toothbrushes once in 2 months and there was a significant difference ( $p=0.002)$ between both the genders. Almost $26.51 \%$ of the students had never visited a dentist in their lifetime, whereas $27.90,18.23$, and $27.34 \%$ had consulted a dentist within 6 months, between 6 and 12 months, and between 1 and 2 years respectively. Around $43.64 \%$ of the participants were cognizant of the fact that improper brushing is the reason of tooth decay. The preference of consuming alcohol was higher (47\%) than the habit of tobacco $(32.6 \%)$. Nearly $37.6 \%$ of participants were of the opinion that lack of proper brushing and flossing can cause bad breath whereas 22\% did not know the reason and $40 \%$ answered it wrongly (Table 2 ).

The concept of the usage of tobacco was assessed by asking six questions to which participants had to respond with "strongly agree," "agree," "disagree," or "strongly disagree." Approximately $86 \%$ of the participants agreed that discoloration of tooth is the consequence of tobacco use and the difference was statistically significant $(p=0.05)$ when compared between male and female students. Almost $80 \%$ of the students also agreed on the fact that tobacco causes gum diseases. Nearly $91 \%$ of the students agreed that smoking increases the risk of cancer and the difference was highly significant between males and females. Approximately $80 \%$ were also aware that heavy smoking and use of smokeless tobacco can impair oral health and cause cancer. Around $77 \%$ of students were in view that use of alcohol has detrimental effect on oral health (Table 3).

\section{DISCUSSION}

Various studies have been conducted to assess the knowledge, attitude, and practices on oral hygiene in students with a background of health sciences. ${ }^{4-6}$ Student community all together play a vital role in bringing about a behavioral change in the society. ${ }^{7}$ With this in view, the present study was conducted to assess oral 
Table 2: Response of the participants on oral hygiene knowledge and practices

\begin{tabular}{|c|c|c|c|}
\hline Questions & Options & Response of the participants (\%) & $p$-value \\
\hline \multirow[t]{4}{*}{ Frequency of brushing in a day } & Once a day & 63.5 & 0.315 \\
\hline & Twice a day & 25.4 & \\
\hline & Thrice a day & 5.8 & \\
\hline & After every meal & 5.2 & \\
\hline \multirow[t]{4}{*}{ Usage of fluoridated toothpaste for brushing } & Always & 45.6 & 0.07 \\
\hline & Often & 23.5 & \\
\hline & Rarely & 16.6 & \\
\hline & Never & 14.3 & \\
\hline \multirow[t]{4}{*}{ Frequency of flossing } & After every meal & 14.6 & 0.71 \\
\hline & Once a day & 22.9 & \\
\hline & Rarely & 25.4 & \\
\hline & Never & 37.0 & \\
\hline \multirow[t]{4}{*}{ Frequency of snacking habit } & Once a day & 33.3 & 0.24 \\
\hline & Twice a day & 21.0 & \\
\hline & More than twice a day & 33.7 & \\
\hline & Never & 12.2 & \\
\hline \multirow[t]{4}{*}{ Interval for change of toothbrush } & Once in 2 months & 34.5 & $0.002^{*}$ \\
\hline & Once in 3 months & 24.9 & \\
\hline & Once in 6 months & 27.1 & \\
\hline & Once in a year & 13.5 & \\
\hline \multirow[t]{4}{*}{ Last dental visit } & $<6$ months & 27.9 & 0.54 \\
\hline & Between 6 and 12 months & 18.2 & \\
\hline & Between 1 and 2 years & 27.3 & \\
\hline & Never & 26.5 & \\
\hline \multirow[t]{4}{*}{ Reason for tooth decay } & Gutka chewing & 31.5 & 0.74 \\
\hline & Smoking & 16.0 & \\
\hline & Improper brushing & 43.6 & \\
\hline & Having chewing gum & 8.8 & \\
\hline \multirow[t]{4}{*}{ Habit of using tobacco products } & Yes & 15.2 & 0.132 \\
\hline & Yes, used to but I have quit & 17.1 & \\
\hline & No, I use occasionally & 17.4 & \\
\hline & Never & 50.3 & \\
\hline \multirow[t]{4}{*}{ Habit of consuming alcohol } & Yes & 19.9 & 0.132 \\
\hline & Yes, used to but I have quit & 11.6 & \\
\hline & No, I use occasionally & 26.8 & \\
\hline & Never & 41.7 & \\
\hline \multirow[t]{4}{*}{ Cause of bad breath } & Food, such as garlic and onion & 33.4 & 0.61 \\
\hline & Lack of proper brushing and flossing & 37.6 & \\
\hline & Hormonal fluctuations & 6.9 & \\
\hline & Do not know & 22.1 & \\
\hline
\end{tabular}

${ }^{*} p \leq 0.05$

Table 3: Concepts of participants on tobacco usage

\begin{tabular}{llllll}
\hline Questions & Strongly agree & Agree & Disagree & Strongly disagree & $p$-value \\
\hline Tobacco usage causes discoloration of tooth & 38.4 & 48.1 & 9.9 & 3.6 & $0.05^{*}$ \\
Tobacco usage causes gum diseases & 27.3 & 53.3 & 13.3 & 6.1 & 0.72 \\
Heavy smoking impairs oral health & 35.9 & 49.7 & 9.4 & 5.0 & 0.34 \\
Tobacco smoking increases the risk of oral cancer & 44.8 & 46.4 & 5.8 & 3.0 & $0.00^{*}$ \\
Tobacco chewing increases the risk of oral cancer & 34.5 & 47.5 & 12.4 & 5.5 & 0.63 \\
Consumption of alcohol impairs oral health & 26.5 & 50.6 & 14.4 & 8.6 & 0.90 \\
\hline
\end{tabular}

${ }^{*} \mathrm{p} \leq 0.05$ 
hygiene-related practices and knowledge on side effects of tobacco usage in professional students of a private engineering college.

Among these students, $63.5 \%$ brushed once a day which was in consonance with the study by $\mathrm{Kumar}^{7}$ $(66 \%)$. A higher percentage (67\%) of students brushed twice daily in studies done by Kakkad et $\mathrm{al}^{8}$ and Peltzer and Pengpid ${ }^{9}$ in comparison to our study (25.4\%). Few studies also reported similar observation to ours. ${ }^{10-12}$ This may be attributed to the lack of oral health knowledge or negligence due to busy study schedule.

About two-thirds (69\%) of participants in this study used fluoridated toothpaste, which was higher than a study done by Doshi et $\mathrm{al}^{13}$ where $48.5 \%$ of engineering students and $58.7 \%$ of medical students used fluoridated toothpastes. Approximately $55 \%$ of engineering students in North Bengaluru and nonprofessional college students in Chennai believe that toothpastes containing fluoride prevent tooth decay, rendering them stronger. ${ }^{12}$ This shows the adequate knowledge of the participants regarding the benefits of fluoride in the toothpaste.

Dental flosses are useful aids designed specifically to clean the interdental areas. ${ }^{14}$ Approximately $63 \%$ of engineering students in our study flossed, out of which $37.5 \%$ flossed at least daily which was in consonance with the study done in San Francisco, ${ }^{15}$ North-East Ontario, ${ }^{16}$ and $\operatorname{Iraq}^{4}$ where $75 \%, 44 \%$, and over half of the students respectively, used dental floss on a daily basis. Nevertheless, many studies showed that use of dental floss was not very popular. ${ }^{7,12,17}$ Almost $40 \%$ of students in Bhubaneswar city were in view that lack of proper brushing and flossing is the reason for tooth decay and bad breath.

Nearly $88 \%$ of students in the present study have a habit of snacking, which is much higher than studies by Kakkad et $\mathrm{al}^{8}(49.60 \%)$, Kumar $^{7}(47 \%)$, and Prasad and Shankar ${ }^{10}(33.7 \%)$. This could be attributed to the availability of snacks in the vicinity of the college and long breaks between the classes. Still a minority of participants $(12.15 \%)$ claimed that they did not have a habit of snacking. On a comparative perspective, studies have shown that a low percentage of dentists also have the habit of consuming sugar-containing snacks. ${ }^{4-6,18}$

In the present study, approximately $60 \%$ of the students changed their toothbrush within 1 to 3 months in contrast to a higher percentage $(80 \%)$ seen in engineering and MBA/BBM students of Bengaluru. ${ }^{17,13}$ The attitude of regularly changing toothbrush was much lower (10\%) in law students of Chennai. ${ }^{7}$ Moreover, it was found that females demonstrated a significant positive attitude as compared to male students in terms of change of toothbrushes and the difference was statistically significant $(p=0.002)$. This infers that these students are unaware of the fact that prolonged usage of toothbrushes not only decreases effectiveness in cleaning of plaque but also causes trauma to gingival tissue. They should be educated about the importance of changing of toothbrush at regular intervals.

Dentists play a major role in maintaining overall dental health. Nearly $28 \%$ of the population had at least visited their dentist once in $<6$ months which was consistent with the result of studies by Doshi et $\mathrm{al}^{13}$ and Al-Hussaini et al. ${ }^{19}$ Almost $27 \%$ of individuals had never been to a dentist, which was in consonance with the study done by Gopikrishna et $\mathrm{al}^{17}$ among engineering students of Bengaluru. A still lower percentage of nonprofessional students $(14.1 \%)$ had visited a dentist within 1 year, though $73.9 \%$ were in opinion that one should visit a dentist once in 6 months. ${ }^{12}$ This reflects the poor awareness among the engineering students regarding early diagnosis of dental caries and periodontal diseases and thereby maintenance of overall oral health.

Formidable rates of alcohol abuse have been reported in several studies. In a study by $\mathrm{O}^{\prime}$ Callaghan et al, ${ }^{20}$ 70 to $90 \%$ of students consumed alcohol regularly in Australia. Another Australian study revealed that $88 \%$ of students drank alcohol with $45 \%$ of them drinking weekly. ${ }^{21}$ In this study, about $45 \%$ of students consume alcohol whereas $75 \%$ of them agreed that consumption of alcohol impairs oral health. A study by Sharma ${ }^{22}$ showed that $38 \%$ of students consumed alcohol and $53 \%$ of the engineering college students had average knowledge regarding alcohol consumption and its ill-effects. Shavi et $\mathrm{al}^{23}$ reported that $22.01 \%$ of the engineering students in Jaipur consumed alcohol at a sensible level and 23.73\% of the students were involved in binge drinking. These educational institutions harbor the majority of young adult population aged between 18 and 24 years, thus playing a substantial role in reducing risky drinking among this age group.

In a study by Jalilvand et $\mathrm{al}^{24} 52 \%$ of the engineering students chewed tobacco in the form of Paan. Berg et $\mathrm{a}^{25}$ reported a low rate of smoking $(21 \%)$ in students majoring in engineering. In our study, $32.5 \%$ of students had a habit of using tobacco products while $80 \%$ of students were in view that usage of tobacco causes discoloration of tooth, gum diseases, and increased risk of oral cancer. Nearly $85 \%$ of them were also aware of the fact that smoking impairs oral health and increases the risk of cancer. Almost $18.61 \%$ of the engineering students of Jaipur used to smoke tobacco, and nearly $8.50 \%$ used smokeless tobacco as reported by Shavi et $\mathrm{al}^{23}$ and the values were quite low in comparison to our study.

This study was limited by the survey design being self-reported behaviors which may have led to over reporting of oral hygiene practices. The psychological and 
socioeconomic factors were not taken into consideration. Moreover, small sample size of 362 students may limit the generalizability of data.

\section{CONCLUSION}

Knowledge with respect to oral health among the engineering students of Bhubaneswar city is adequate regarding using fluoridated toothpaste and flosses. However, an unhealthy snacking habit, overusage of toothbrushes, consumption of alcohol, and practicing tobacco habit show the lack of oral health knowledge in these students. We, as dental health professionals, should instill a more positive attitude toward visiting a dentist regularly and warn them against the ill-effects of tobacco. Oral health promotion programs providing education regarding proper eating habits, effective maintenance of oral hygiene, and avoiding tobacco usage can go a long run in improving oral health among the students.

\section{Clinical Significance}

Adequate knowledge about oral health and following proper oral hygiene practices have a great clinical significance. Optimal knowledge keeps the mouth clean, thus preventing various oral diseases. Maintenance of proper oral health results in reduction of all gum diseases. Studies have shown that there is a decrease in the incidence of dental caries in people who maintained good oral hygiene. It is also well documented that healthy mouth is essential for a healthy body. Hence, studies like ours would give a correct idea about the present scenario in terms of oral hygiene and tobacco usage in young individuals. This can form the basis for oral health education and tobacco cessation program. Moreover, as the habit of tobacco usage starts early during college life, adequate knowledge about its ill-effects would prevent deadly diseases, such as potentially malignant disorders and oral cancer.

\section{REFERENCES}

1. Health Topics: Oral Health. Geneva: World Health Organization (WHO). 2015. Available from: http://www. who.int/oral_health/publications/2015/en/

2. Kubota M, Yanagita M, Mori K, Hasegawa S, Yamashita M, Yamada S, Kitamura M, Murakami S. The effects of cigarette smoke condensate and nicotine on periodontal tissue in a periodontitis model mouse. PLoS One 2016 May;11(5):e0155594.

3. Zhu L, Petersen PE, Wang HY, Bian JY, Zhang BX. Oral health knowledge, attitudes and behaviour of children and adolescents in China. Int Dent J 2003 Oct;53(5):289-298.

4. Awan KH, Hammam MK, Warnakulasuriya S. Knowledge and attitude of tobacco use and cessation among dental professionals. Saudi Dent J 2015 Apr;27(2):99-104.

5. Gopinath V. Oral hygiene practices and habits among dental professionals in Chennai. Indian J Dent Res 2010 Apr-Jun;21(2):195-200.
6. Kumar KK, Ramachandra S, Babu AR, Reddy BVR. A study on oral hygiene practices and habits among dental professionals in Andhra Pradesh. J Orofac Sci 2011 Sep;3(2):4-9.

7. Kumar MP. Knowledge, attitude and practices towards oral health among law students. J Pharm Sci 2016 Aug;8(7):650-653.

8. Kakkad DN, Murali R, Krishna M, Yadav S, Yalamalli M, Kumar AV. Assessment of oral hygiene knowledge, attitude and practices among engineering students in North Bangalore: a cross-sectional survey. Int J Sci Stud 2015 Apr;3(1):84-89.

9. Peltzer K, Pengpid S. Oral health behaviour and social and health factors in university students from 26 low, middle and high income countries. Int J Environ Res Public Health 2014 Nov;11(12):12247-12260.

10. Prasad AK, Shankar S. Oral health KAP of first year engineering students of KSR College of technology, Thiruchengode, the future rulers. J Indian Assoc Public Health Dent 2010;8(16):143-147.

11. Gasgoos SS, Jazrawi KH, Al-Ajrab MG. Dental health knowledge, attitude and behavior among first year university students, Mosul. Al-Rafidain Dent J 2007;7(2):138-152.

12. Kumar SM, Singarampillay V, Natrajan S. Oral health awareness among two non professional college students in Chennai, India - a pilot study. Int J Sci Res Publ 2012 May;2(5):1-5.

13. Doshi D, Baldava P, Anup N, Sequeira PS. A comparative evaluation of self-reported oral hygiene practices among medical and engineering university students with access to health-promotive dental care. J Contemp Dent Pract 2007 Jan;8(1):68-75.

14. Torkzaban P, Arabi SR, Sabounchi SS, Roshanaei G. The efficacy of brushing and flossing sequence on control of plaque and gingival inflammation. Oral Health Prev Dent 2015 Jun;13(3):267-273.

15. Walsh MM. Effects of school-based dental health education on knowledge, attitudes and behavior of adolescents in San Francisco. Community Dent Oral Epidemiol 1985 Jun;13(3):143-147.

16. Hamilton ME, Coulby WM. Oral health knowledge and habits of senior elementary school students. J Public Health Dent 1991 Fall;51(4):212-219.

17. Gopikrishna V, Bhaskar NN, Kulkarni SB, Jacob J, Sourabha KG. Knowledge, attitude, and practices of oral hygiene among college students in Bengaluru city. J Indian Assoc Public Health Dent 2016 Mar;14(1):75-79.

18. Tseveenjav B, Vehkalahti M, Murtomaa H. Oral health and its determinants among Mongolian dentists. Acta Odontol Scand 2004 Feb;62(1):1-6.

19. Al-Hussaini R, Al-Kandari M, Hamadi T, Al-Mutawa A, Honkala S, Memon A. Dental health knowledge, attitudes and behaviour among students at the Kuwait University Health Sciences Centre. Med Princ Pract 2003 Oct-Dec;12(4):260-265.

20. O'callaghan F, Callan VJ, Wilks J. Extending upon student drinking patterns in an Australian population. Drug Alcohol Rev 1990 Jul;9(3):239-244.

21. Davey JD, Davey TM, Obst PL. Alcohol consumption and drug use in a sample of Australian university students. Youth Stud Aust 2002 Sep;21(3):25-32.

22. Sharma MK. A study to determine the prevalence of alcohol consumption among engineering college students and to assess their knowledge and attitude regarding alcohol consumption and its ill effects in selected private engineering colleges of Rajasthan. Int J Adv Nurs Manag 2016 Jan;4(3):214-218. 
23. Shavi GR, Chaudhary P, Agrawal M, Joshi P, Khan M, Bhaskar RK. Alcohol and drug use among Jaipur based engineering students: a questionnaire based observational study. Int J Prev Public Health Sci 2015 May-Jun;1(1):9-13.

24. Jalilvand M, Nikmanesh Z, Kazemi Y, Emamhadi MA. Smokeless tobacco use among university students: a cross-sectional study in Iran, Sistan Baluchestan Province, 2008. Iran J Psychiatr Behav Sci 2010 Jan;4(1):23-29.

25. Berg CJ, Klatt CM, Thomas JL, Ahluwalia JS, An LC. The relationship of field of study to current smoking status among college students. Coll Stud J 2009 Sep;43(3): 744-754. 